\title{
Correction to: Toward an integrated genetic model for vent-distal SEDEX deposits
}

\author{
D. F. Sangster ${ }^{1}$
}

Published online: 29 November 2017

(C) Springer-Verlag GmbH Germany 2017

\section{Correction to: Miner Deposita}

https://doi.org/10.1007/s00126-017-0755-3

The original version of this article unfortunately contained a mistake. Fig. 5(b) was originally published with an incorrect label. The correct version of this figure is provided here and the original article was corrected.

The online version of the original article can be found at https://doi.org/ 10.1007/s00126-017-0755-3.

$\triangle \quad$ D. F. Sangster

dsangster@sympatico.ca

1 Ottawa, ON, Canada 

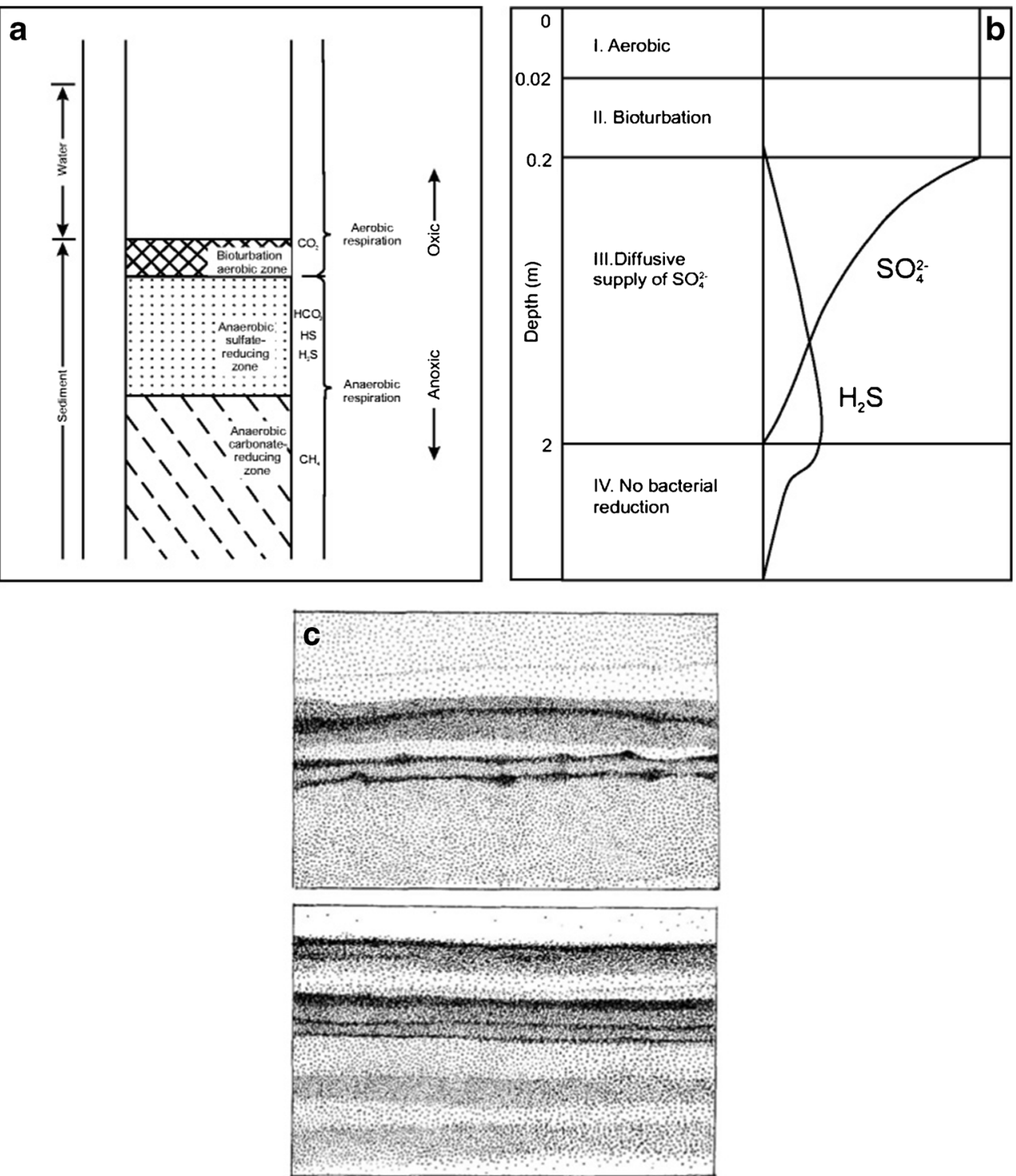